
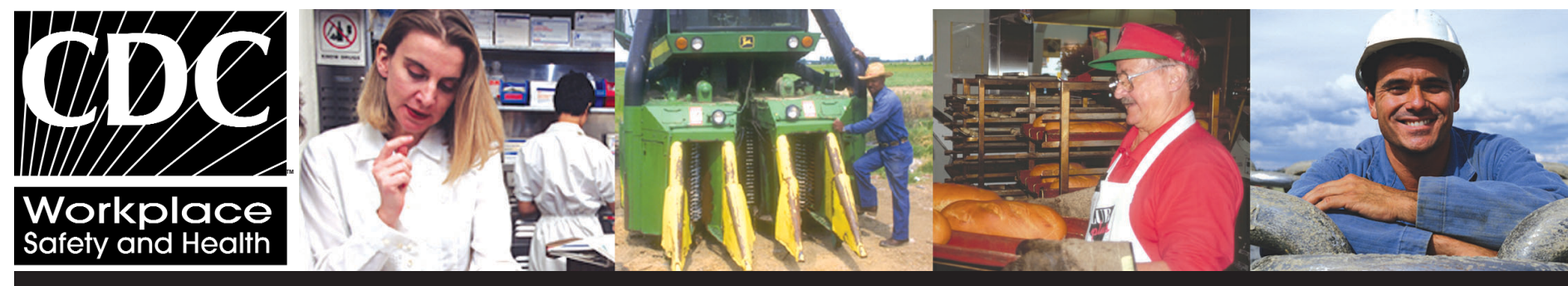

\title{
National Institute for Occupational Safety and Health (NIOSH) Fact Sheet
}

The National Institute for Occupational Safety and Health (NIOSH) is the federal agency responsible for conducting research and making recommendations for the prevention of work-related injury and illness. NIOSH is part of the Centers for Disease Control and Prevention (CDC) in the Department of Health and Human Services.

\section{NIOSH Origins and Mission}

The Occupational Safety and Health Act of 1970 created both NIOSH and the Occupational Safety and Health Administration (OSHA). OSHA is in the U.S. Department of Labor and is responsible for developing and enforcing workplace safety and health regulations. NIOSH is in the U.S. Department of Health and Human Services and is an agency established to help assure "safe and healthful working conditions for working men and women by providing research, information, education, and training in the field of occupational safety and health."

NIOSH provides national and world leadership to prevent work-related illness, injury, disability, and death by gathering information, conducting scientific research, and translating the knowledge gained into products and services. NIOSH's mission is critical to the health and safety of every American worker. Each day, an average of 9,000 U.S. workers sustain disabling injuries on the job, 16 workers die from an injury suffered at work, and 137 workers die from work-related diseases. The Liberty Mutual 2002 Workplace Safety Index estimates that direct costs for occupational injuries in 1999 rose to $\$ 40.1$ billion, with indirect costs reaching over $\$ 200$ billion.

\section{Strategic Goals}

The Institute's responsibilities include:

$\rightarrow$ Conducting a focused program of research to reduce injuries and illnesses among workers in high-priority areas and high-risk sectors, including mining, agriculture, construction, and health care. $\rightarrow$ Implementing and maintaining a system of surveillance for major workplace illnesses, injuries, exposures, and health and safety hazards.

$\rightarrow$ Increasing prevention activities through workplace evaluations, interventions, and recommendations.

$\rightarrow$ Providing workers, employers, the public, and the occupational safety and health community with information, training, and capacity to prevent occupational injuries and illnesses.

\section{NIOSH Locations}

NIOSH is a professionally diverse organization with a staff of over 1,400 people representing a wide range of disciplines including epidemiology, medicine, industrial hygiene, safety, psychology, engineering, chemistry, and statistics. NIOSH is headquartered in Washington, DC, with research laboratories and offices in Cincinnati, OH, Morgantown, WV, Pittsburgh, PA, Spokane, WA and Atlanta, GA.

\section{NIOSH Research}

NIOSH scientists work in multidisciplinary teams and carry out a focused program of intramural and extramural research to prevent or reduce work-related injury and illness. In 1996, NIOSH and over 500 partners established the National Occupational Research Agenda (NORA), a framework to guide the efforts of the occupational safety and health community in 21 priority research areas. NORA encompasses research areas such as traumatic injury, asthma and chronic obstructive pulmonary disease, hearing loss, and control technologies. These priority areas were identified through extensive input from NIOSH's federal and non-federal partners. Since 1996, NIOSH has aligned its intramural and extramural research to increase its investment in NORA priority areas.

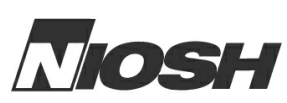




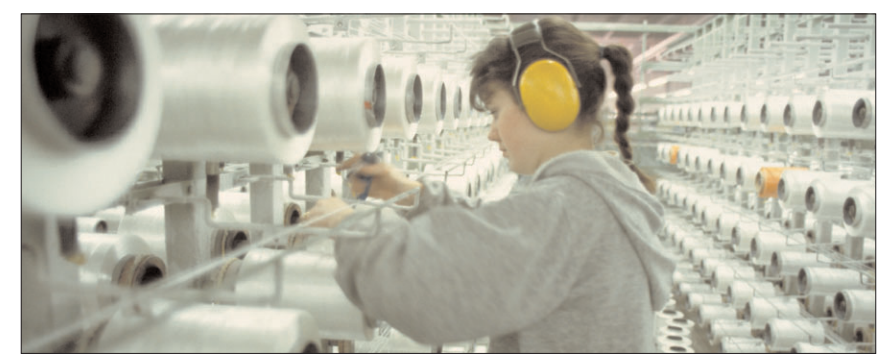

\section{Recent Research Accomplishments}

NIOSH research has brought about important progress in occupational safety and health. NIOSH has:

$\rightarrow$ Developed virtual reality technology to simulate elevated workplaces to better study the risk factors for initiating a fall, the major cause of workplace fatalities in the construction industry.

$\rightarrow$ Evaluated the effectiveness of ultraviolet germicidal irradiation to prevent the transmission of tuberculosis in health care settings.

$\rightarrow$ Evaluated state-of-the-art lifting equipment to eliminate low-back injuries among nursing aides, orderlies, and attendants.

$\rightarrow$ Identified industries and occupations with increased risk for COPD and estimated the proportion due to workplace exposures by industry and occupation.

$\rightarrow$ Defined the current state of noise control technology for the mining industry and conducted over 3600 audiometric tests while training workers to protect their hearing.

\section{NIOSH Prevention, Surveillance, and Training and Communication Programs}

$\rightarrow$ The NIOSH Health Hazard Evaluation (HHE) Program responds to requests for workplace evaluations from employers, employees and their representatives, and other agencies. Through the HHE program, NIOSH identifies current hazards and recommends practical, scientifically valid solutions for reducing exposures and preventing disease, injury, and disability. A recent HHE involved an investigation of an outbreak of a rare respiratory disease at a microwave popcorn processing plant in Missouri. NIOSH determined that the workers' illness was due to exposure to inhaled vapors from artificial butter flavorings. The company instituted NIOSH recommendations to protect its workers, and NIOSH scientists continue laboratory and outreach efforts to further characterize the nature and the scope of the problem.

$\rightarrow$ In 1998, NIOSH established the Fire Fighter Fatality Investigation and Prevention Program to reduce fire fighter line- of-duty deaths and injuries through surveillance, investigations of fatalities, and development and dissemination of practical recommendations. Individual reports from the program are disseminated to over 25,000 volunteer and career fire departments across the country.

$\rightarrow$ The National Personal Protective Technology Laboratory (NPPTL) was established at the NIOSH Pittsburgh site to provide leadership for the prevention of injury and illness among workers who must rely on personal protective equipment, including respirators, gloves, and hard hats. NPPTL's strategic research program will ensure that the development of new personal protective equipment will meet real needs as work settings, technologies, and worker populations change and new threats emerge.

$\rightarrow \mathrm{NIOSH}$ conducts and supports a variety of programs to track occupational injuries and illnesses. These include the Sentinel Event Notification System for Occupational Risks (SENSOR), which is a collaborative effort with state health departments to improve the recognition and prevention of occupational sentinel health events, such as asthma, silicosis, amputations, burns, dermatitis, and noise-induced hearing loss. NIOSH also supports the Adult Blood Lead Epidemiology and Surveillance Program (ABLES) in over two thirds of the states. Through ABLES, states track and respond to cases of excessive lead exposure and develop broader intervention activities.

$\rightarrow$ Established in 1990, the NIOSH Agricultural Centers Program provides a national resource to address agricultural health and safety problems through research, education, prevention, and intervention efforts. In 2001, nine regional Centers nationwide developed over 370 collaborative programs with other regional and national agricultural organizations.

$\rightarrow$ NIOSH supports training of occupational safety and health professionals and researchers through 16 regional Education and Research Centers (ERCs) and 35 Training Project Grants (TPGs) in 22 states and Puerto Rico. These programs are critical for meeting the increasing demand for occupational physicians, occupational nurses, industrial hygienists and other safety professionals. The ERCs also provide education to practicing professionals through extensive continuing education programs.

$\rightarrow$ The NIOSH Web site provides access to the full range of NIOSH information and publications. In 2002, the site supported nearly 500,000 visitor sessions a month and the average monthly page views totaled 1.75 million. NIOSH is also communicating occupational safety and health information in Spanish through NIOSH en Español.

\section{Safer. Healthier.Peoplem}

For additional information, contact NIOSH at 1-800-35-NIOSH (1-800-356-4674)

Fax: 513-533-8573, or visit the NIOSH Web site at: www.cdc.gov/niosh 